\title{
Conformational changes and loose packing promote $E$. coli Tryptophanase cold lability
}

\author{
Anna Kogan ${ }^{1}$, Garik Y Gdalevsky1, Rivka Cohen-Luria ${ }^{1}$, Yehuda Goldgur ${ }^{1}$, \\ Robert S Phillips ${ }^{2}$, Abraham H Parola*1 and Orna Almog*3
}

\begin{abstract}
Address: ${ }^{1}$ Department of Chemistry, Ben-Gurion University of the Negev, POB 653, Beer-Sheva 84105, Israel, ${ }^{2}$ Departments of Chemistry and Biochemistry and Molecular Biology, University of Georgia, Athens, GA 30602, USA and ${ }^{3}$ Department of Clinical Biochemistry, Faculty of Health Sciences, Ben-Gurion University, Beer-Sheva 84105, Israel

Email: Anna Kogan - annak@bgu.ac.il; Garik Y Gdalevsky - garikg@bgu.ac.il; Rivka Cohen-Luria - riky@bgu.ac.il;

Yehuda Goldgur - goldgury@mskcc.org; Robert S Phillips - rsphillips@chem.uga.edu; Abraham H Parola* - aparola@bgu.ac.il; Orna Almog* - almogo@bgu.ac.il

* Corresponding authors
\end{abstract}

Published: 8 October 2009

BMC Structural Biology 2009, 9:65 doi:10.1 186/1472-6807-9-65

This article is available from: http://www.biomedcentral.com/1472-6807/9/65

(c) 2009 Kogan et al; licensee BioMed Central Ltd.

This is an Open Access article distributed under the terms of the Creative Commons Attribution License (http://creativecommons.org/licenses/by/2.0), which permits unrestricted use, distribution, and reproduction in any medium, provided the original work is properly cited.
Received: 7 January 2009

Accepted: 8 October 2009

\begin{abstract}
Background: Oligomeric enzymes can undergo a reversible loss of activity at low temperatures. One such enzyme is tryptophanase (Trpase) from Escherichia coli. Trpase is a pyridoxal phosphate (PLP)-dependent tetrameric enzyme with a Mw of $210 \mathrm{kD}$. PLP is covalently bound through an enamine bond to Lys 270 at the active site. The incubation of holo $E$. coli Trpases at $2^{\circ} \mathrm{C}$ for $20 \mathrm{~h}$ results in breaking this enamine bond and PLP release, as well as a reversible loss of activity and dissociation into dimers. This sequence of events is termed cold lability and its understanding bears relevance to protein stability and shelf life.
\end{abstract}

Results: We studied the reversible cold lability of E. coli Trpase and its Y74F, C298S and W330F mutants. In contrast to the holo E. coli Trpase all apo forms of Trpase dissociated into dimers already at $25^{\circ} \mathrm{C}$ and even further upon cooling to $2^{\circ} \mathrm{C}$. The crystal structures of the two mutants, Y74F and $\mathrm{C} 298 \mathrm{~S}$ in their apo form were determined at $1.9 \AA$ resolution. These apo mutants were found in an open conformation compared to the closed conformation found for $P$. vulgaris in its holo form. This conformational change is further supported by a high pressure study.

Conclusion: We suggest that cold lability of $E$. coli Trpases is primarily affected by PLP release. The enhanced loss of activity of the three mutants is presumably due to the reduced size of the side chain of the amino acids. This prevents the tight assembly of the active tetramer, making it more susceptible to the cold driven changes in hydrophobic interactions which facilitate PLP release. The hydrophobic interactions along the non catalytic interface overshadow the effect of point mutations and may account for the differences in the dissociation of $E$. coli Trpase to dimers and $P$. vulgaris Trpase to monomers.

\section{Background}

Enzymes can undergo a reversible loss of activity at low temperatures, a process that is termed cold inactivation
$[1,2]$. This phenomenon is found in a widespread variety of oligomeric enzymes, e.g, pyrophosphatase [3], pyruvate carboxylase [4], alcohol dehydrogenase [5], as well as 
PLP-dependent enzymes such as glutamic acid decarboxylase [6] and tryptophanase (Trpase) [7-9]. It has been proposed that cooling evokes major changes in hydrophobic interactions which leads to destabilization of the enzyme quaternary structure concomitant with dissociation into its corresponding subunits [10]. These changes can in most cases be reversed after re-warming [11,12]. Sometimes, however, cold-induced dissociation is followed by an aggregation step, which causes the irreversibility of the process [13-16]. It is believed that at low temperatures the entropic term for association becomes less favorable since the solvent molecules released upon association are more ordered. In general, the models for cold inactivation predict that the pivotal role in cold inactivation is played by hydrophobic interactions [17], but direct experimental evidence is lacking.

E. coli tryptophanase (tryptophan indole-lyase, Trpase, EC 4.1.99.1) is a pyridoxal 5'-phosphate (PLP)-dependent enzyme that catalyses $\alpha, \beta$-elimination and $\beta$-replacement reactions of L-tryptophan. The molecular weight of Trpase from different species ranges from 200 to $220 \mathrm{kD}$. Trpase consists of four identical subunits ( $\sim 52 \mathrm{kD}$ per monomer), each of which covalently binds one molecule of PLP. The tetramer possesses a D2 symmetry, therefore it is a dimer of dimers with two different dimeric interfaces: a catalytic interface and a non-catalytic interface (Figure 1) [18-26].

Wild-type (wt) E. coli Trpase in its holo form undergoes a very slow and reversible inactivation after incubation at $2{ }^{\circ} \mathrm{C}$ for several hours. The catalytic activity can be restored by incubation at room temperature or $37^{\circ} \mathrm{C}$ for several hours $[11,12]$. Using kinetic spectrophotometric methods and size-exclusion chromatography we have previously shown that the inactivation process is linked to the cleavage of the PLP-Lys 270 aldimine bond and to the dissociation of the tetrameric form of Trpase into dimers [27]. Interestingly, the dissociation of E. coli Trpase never proceeds beyond dimers. It was suggested that the cooling of wt Trpase and its mutants has two effects - it weakens hydrophobic interactions and it causes the release of PLP from the active site. In order to identify which of these processes most contributes to the cold lability of $E$. coli Trpase we studied cold and high pressure inactivation, cold dissociation and the crystal structure of several Trpase variants and mutants. The mutation sites are located in different interfaces of the tetramer (i.e., the catalytic and the non-catalytic interfaces [18]) and were originally designed for understanding the contribution of each mutation to the assembly into the catalytic active tetramer.

The crystal structure of holo Trpase isolated from Proteus vulgaris [18] and of another two crystal structures of E. coli

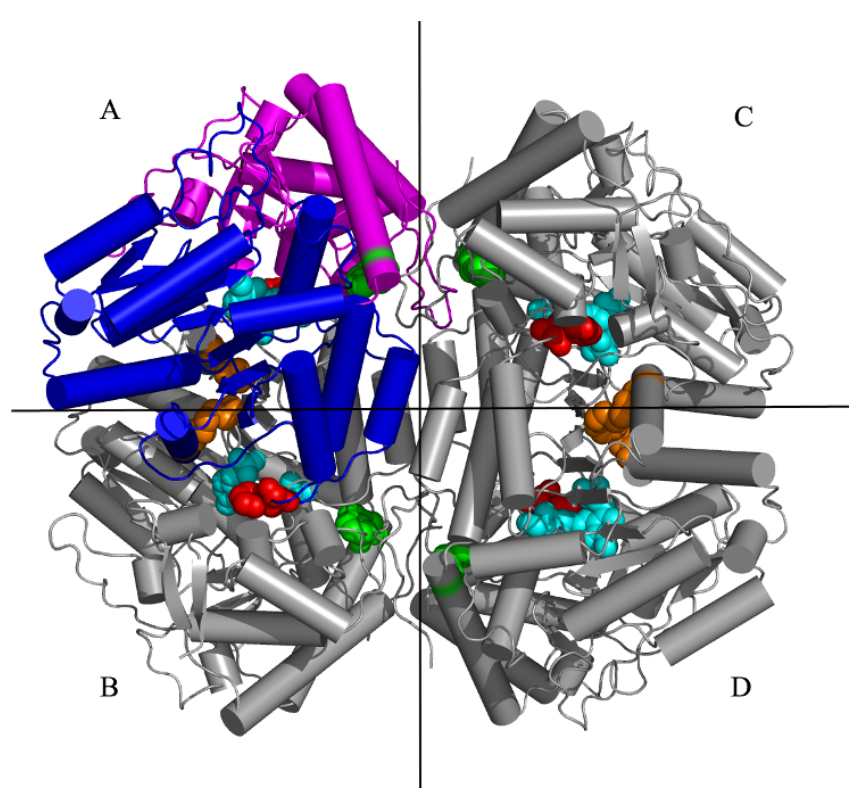

Figure I

The crystal structure of tetrameric form Trpase of $E$. coli created by symmetry operation of single monomer. Molecule A is colored by domains; large domain is colored in blue and small domain in magenta. The other three monomers of the tetramer are colored in gray. The non-catalytic axis (vertical) and catalytic axis (horizontal) are shown as lines perpendicular to each other. Mutation sites of residue 74 (orange), residue 298 (red), and 330 (green) as well as the PLP molecule (cyane) are shown as CPK.

Trpases in their apo form were determined $[28,29]$. Both crystal structures of apo E. coli Trpases share the same fold as the holo P. vulgaris Trpase, but structural alignment of the three crystal structures revealed significant differences in the relative orientation of the two domains of the enzyme [29]. We compared these known crystal structures to the two new crystal structures of Trpase mutants we determined in order to gain structural insights into the cold-induced conformational changes and PLP release. In addition, we sought structural themes to account for the stability of $E$. coli dimers which do not dissociate into monomers as do those from $P$. vulgaris.

\section{Results}

\section{Enzymatic activity measurements}

Subsequent to incubation at $2{ }^{\circ} \mathrm{C}$, wt Trpase lost about $35 \%$ of its activity while the W330F and C298S mutants lost about $90 \%$ of their activity (Table 1). The Y74F mutant has low activity at $25^{\circ} \mathrm{C}$ and its residual activity was further reduced by cooling (Table 1).

The cold inactivation of the W330F and C298S mutants was similar, about $90 \%$, which is much higher than that of the wt Trpase (only 35\%). Residue 330 of E. coli Trpase 
Table I: Specific activity of wt-Trpase and its mutants at $25^{\circ} \mathrm{C}$ and after cooling to $2^{\circ} \mathrm{C}$ in Tricine $-\mathrm{KCl}$ buffer, $\mathrm{pH}=7.5$.

\begin{tabular}{|c|c|c|}
\hline Trpase & $\begin{array}{c}\text { Specific activity } \\
25^{\circ} \mathrm{C}\end{array}$ & $\begin{array}{c}\text { (Units/mg) } \\
2^{\circ} \mathrm{C}\end{array}$ \\
\hline wt & $45.7 \pm 2.5$ & $29.7 \pm 1.7$ \\
\hline W330F & $42.8 \pm 3.2$ & $5.0 \pm 1.4$ \\
\hline C298S & $36.9 \pm 2.9$ & $3.7 \pm 0.8$ \\
\hline Y74F* & $0.2 \pm 0.05$ & $0.08 \pm 0.03$ \\
\hline
\end{tabular}

*The concentrations of the wt Trpase and of W330F, C298S mutants were $0.3-0.5 \mathrm{mg} / \mathrm{ml}$, while the concentration of the $\mathrm{Y} 74 \mathrm{~F}$ mutant was $10-20 \mathrm{mg} / \mathrm{ml}$.

is located at the non-catalytic interface while residue 298 is located at the catalytic interface (Figure 1), yet both mutants showed a similar loss of activity. Due to the opposite change in hydrophobicity caused by the corresponding mutations (Table 2), the observed loss of activity cannot be attributed to a more hydrophobic residue [30] at the different interfaces. A plausible explanation for the loss in activity is the change in the size of the side chains of the amino acids. In all of these mutations sites the new amino acid is smaller than the wt, and the mutation enlarges the space for the side chain orientation and increases the thermal motion in the respective regions, Table 2[31-33] and references within. These mutations prevent the tight assembly of the tetramer and result in dissociation into dimers, which leads to the observed loss in activity. Although the reduction in size is relatively minor, the effect is four fold amplified since Trpase is a tetrameric enzyme.

In the $\mathrm{Y} 74 \mathrm{~F}$ mutant, the observed loss of activity at $25^{\circ} \mathrm{C}$ is presumably attributed to the proximity of residue 74 to the substrate binding site [34]. In the wt Trpase the hydroxyl group of Tyr74 is hydrogen bonded to both Arg103 (at a $2.9 \AA$ Aistance), and to the phosphate group of PLP (of the neighbouring subunit in the catalytic dimer) through a bridging water molecule. Replacing Y74 by phenylalanine eliminated the hydrogen bonds of the hydroxyl group thereby reducing its affinity towards PLP.
Hence, the Y74F mutant exhibited negligible activity compared to the other Trpases.

\section{Time dependence profile of cold inactivation and dissociation}

The time course of cold inactivation of wt Trpase and its W330F and C298S mutants in Tricine-KCl buffer, pH 7.5 in the presence $0.05 \mathrm{mM}$ PLP is shown in Figure 2. For C298S cold inactivation occurred much faster than that for W330F and wt Trpase. The rate constants of the initial linear phase are $(13.8 \pm 0.3) \times 10^{-3} \mathrm{~min}^{-1},(1.7 \pm 0.1) \times 10^{-}$ ${ }^{3} \mathrm{~min}^{-1}$ and $(0.6 \pm 0.3) \times 10^{-3} \mathrm{~min}^{-1}$ for C298S, W330F and wt Trpase, respectively. Both W330F and C298S exhibit similar $(90 \%)$ total cold inactivation, but the time profile (Figure 2A) revealed a factor of about 8 fold faster kinetics for C298S.

The cold dissociation time profiles revealed the same pattern, with the following initial rate constants: $(3.2 \pm 0.1)$ $\times 10^{-3} \mathrm{~min}^{-1}(0.84 \pm 0.1) \times 10^{-3} \mathrm{~min}^{-1}$ and $(0.42 \pm 0.1) \times 10^{-}$ ${ }^{3} \mathrm{~min}^{-1}$ for C298S, W330F and wt Trpase, respectively (Figure $2 \mathrm{~B}$ ). The rate constants for cold inactivation and dissociation are similar for the wt and the W330F mutant, but in the case of C298S there is a factor of $\sim 4$ between them. This may be attributed to the relative proximity of residue 298 to the PLP and substrate binding sites as well as to its location on the catalytic interface, in contrast to that of the 330 site. The PLP in the C298S mutant is loosely bound allowing, relative to $\mathrm{W} 330 \mathrm{~F}$ and the $\mathrm{wt}$, a quicker cold inactivation and dissociation.

\section{Dissociation of E. coli Trpases to dimers}

The HPLC analyses of $E$. coli Trpase dissociation into dimers are presented in Table 3. The holo wt Trpase and its mutants $\mathrm{C} 298 \mathrm{~S}$ and $\mathrm{W} 330 \mathrm{~F}$ at $25^{\circ} \mathrm{C}$ are tetramers and upon cooling dissociate into dimers: $20 \%$ dissociation took place with the wt Trpase, whereas $60-70 \%$ dissociation took place for the three mutants. It should be noted that mutant $\mathrm{Y} 74 \mathrm{~F}$ dissociates even at $25^{\circ} \mathrm{C}$ (about $17 \%$ ). Unless the concentration of PLP is higher than $5 \mathrm{mM}$,

Table 2: A summary of physical properties of residues affecting cold lability.

\begin{tabular}{|c|c|c|c|c|}
\hline Residue name & Volume $\left(\AA^{3}\right)$ & Hydrophobicity [55] & Location & Comments \\
\hline Tyr74 & 193.6 & -1.3 & On the catalytic interface & $\begin{array}{l}\text { Involved in hydrogen bonding with PLP and Arg } 103 \\
\text { from adjacent subunit }\end{array}$ \\
\hline Phe74 & 189.9 & 2.8 & On the catalytic interface & \\
\hline Trp330 & 227.8 & -0.9 & On the non-catalytic interface & \\
\hline Cys 298 & 108.5 & 2.5 & Close to the catalytic interface & Oxidized with 2-mercaptoethanol \\
\hline Ser 298 & 89.0 & -0.8 & Close to the catalytic interface & \\
\hline Vall 5 & 140.0 & 4.2 & On the non-catalytic interface & Involved in inter subunit $\beta$-sheet network \\
\hline Ile16 & 166.7 & 4.5 & On the non-catalytic interface & Involved in inter subunit $\beta$-sheet network \\
\hline Met $57^{*}$ & 162.9 & 1.9 & On the non-catalytic interface & Involved in inter subunit $\beta$-sheet network \\
\hline
\end{tabular}

* Accordingly to P. Vulgaris numbering 
A

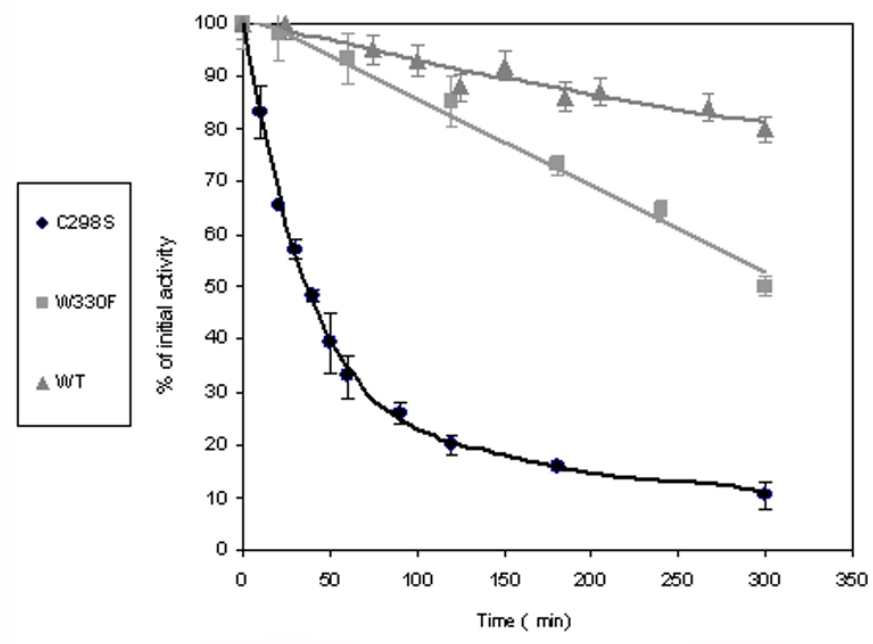

B

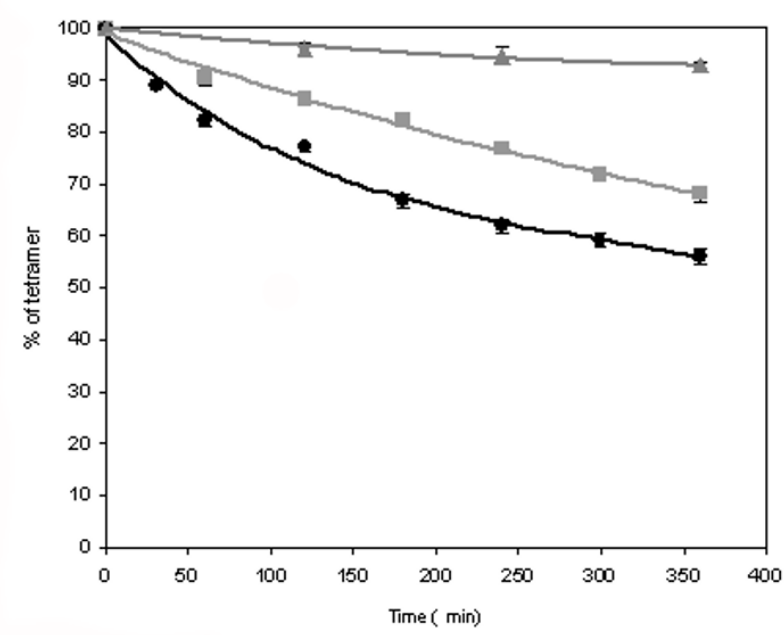

Figure 2

Time dependence of cold inactivation and dissociation of wt Trpase and C298S and W330F mutants incubated at $2^{\circ} \mathrm{C}$ in Tricine- $\mathrm{KCl}$ buffer at $\mathrm{pH} \mathrm{7.5.} \mathrm{Activity} \mathrm{was} \mathrm{measured} \mathrm{by} \mathrm{a} \mathrm{spectrophotometric} \mathrm{method} \mathrm{with} \mathrm{the} \mathrm{chromogenic}$ substrate analog, S-(o-nitrophenyl)-L-cysteine (SOPC); Protein concentration: $1.0 \mathrm{mg} / \mathrm{ml}$.

Y74F exists as a mixture of holo and apo forms which affects the dimer-tetramer equilibrium.

In contrast to the holo forms, all apo forms of Trpase markedly dissociate to dimers, about $70 \%$ at $25^{\circ} \mathrm{C}$ and about $90 \%$ upon cooling to $2^{\circ} \mathrm{C}$ suggesting that PLP has a major effect on the stability of the holo form. Once the PLP molecule is removed, the differences in the extent of dissociation among the wt and the mutants are very small. However, in the holo forms in which PLP is present, the differences between the mutants stem primarily from the effect of mutation, which in all three mutants presumably cause a reduced fit between the dimers relative to the wt form. Thus, the apo form of all Trpases showed a similar lack of stability towards cooling, indicating that the expul-

Table 3: The effect of cooling on the dissociation of wt Trpase and its mutants to dimers.

\begin{tabular}{|c|c|c|}
\hline \multirow[b]{2}{*}{ E. coli Trpase } & \multicolumn{2}{|c|}{ Degree of dissociation to dimers (\%) } \\
\hline & $25^{\circ} \mathrm{C}$ & $2^{\circ} \mathrm{C}$ \\
\hline wt holo & $<3$ & $20 \pm 1$ \\
\hline C298S holo & $<5$ & $64 \pm 1$ \\
\hline W330F holo & $<5$ & $61 \pm 2$ \\
\hline Y74F holo & $17 \pm 3$ & $66 \pm 4$ \\
\hline wt apo & $70 \pm 5$ & $87 \pm 3$ \\
\hline C298S apo & $>80$ & $88 \pm 1$ \\
\hline W330F apo & $69 \pm 4$ & $90 \pm 1$ \\
\hline Y74F apo & $80 \pm 1$ & $83 \pm 2$ \\
\hline
\end{tabular}

For the holo forms, the PLP concentration in Tricine- $\mathrm{KCl}$ buffer is 0.1 $\mathrm{mM}$. sion of PLP renders the apo form equally susceptible to a very pronounced cold driven dissociation.

\section{High pressure studies}

High pressure studies with wt E. coli Trpase revealed a rapid reversible conformational change in which the enzyme exhibits an absorption spectrum with two peaks, one at $338 \mathrm{~nm}$ and the other at $420 \mathrm{~nm}$, corresponding to inactive and active forms of the cofactor, respectively (Figure 3). The $420 \mathrm{~nm}$ form of the enzyme decreases as the pressure is raised, with a concomitant increase in the 338 $\mathrm{nm}$ form, and there is a reasonably good isosbestic point at $374 \mathrm{~nm}$ (Figure 3A), indicating that at equilibrium there are two predominant species. The calculated $\mathrm{K}_{\mathrm{p}}$ shows the expected logarithmic relationship with hydrostatic pressure (Figure $3 \mathrm{~B}$ ), with a $\mathrm{K}_{0}$ (the equilibrium constant involving the two spectroscopically distinctive species with $\lambda_{\max }$ at 420 and $338 \mathrm{~nm}$, at 1 bar) of $0.65 \pm$ 0.03 and $\Delta \mathrm{Vo}=-38 \pm 3 \mathrm{~mL} / \mathrm{mol}$ (where $\Delta \mathrm{Vo}$ is the volume difference associated with the induced conformational change). These data suggest that there is a conformational change associated with the transition between the two absorption peaks, since the relatively large negative value of $\Delta \mathrm{Vo}$ is likely a result of solvation of the exposed protein surface. It is proposed that these two spectroscopic forms of Trpase correspond to the open $(338 \mathrm{~nm})$ and closed $(420 \mathrm{~nm})$ conformations $[35,36]$.

Hydrostatic pressure causes unfolding of proteins because there is a decrease in the volume of the protein-solvent 

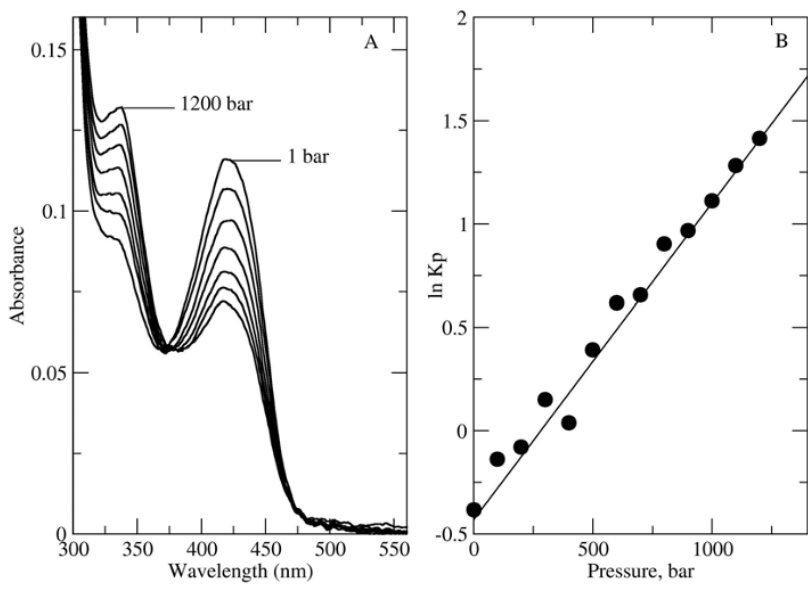

Figure 3

Effect of hydrostatic pressure on the absorption spectra of wt E. coli Trpase (Figure 3A). Plot of the calculated $\mathrm{K}_{\mathrm{p}}$ determined from the absorbance versus the applied hydrostatic pressure (Figure 3B).

system upon unfolding [37]. Generally, three factors are considered to contribute to $\Delta \mathrm{V}_{\mathrm{o}}$ : electrostriction of charged and polar groups that became exposed to solvent upon unfolding or conformational change; collapse of packing defects and internal cavities; volume effects transfer of hydrophobic groups from the protein interior to water. The two first factors provide a negative contribution to $\Delta \mathrm{V}_{\mathrm{o}}$. However, the third factor, the exposure of hydrophobic groups to solvent can give both negative and positive contributions for changes in hydration volumes, depending on pressure and temperature [38].

In the case of the wt Trpase, the conformational change from a closed to an open conformation under increasing pressure is accompanied by large negative value of $\Delta \mathrm{V}_{\mathrm{o}}$. We used the Voronya [39] tool for analyzing the packing of the two crystal structures of wt Trpase which are found in the different conformations (for closed conformation we used pdb entry 2C44; and for the open conformation pdb entry 2OQX). The cavities analysis did not reveal any significant difference between the two conformations. Therefore, the collapse of internal cavities can not be the reason for the large negative value of $\Delta \mathrm{V}_{\mathrm{o}}$. Presumably, the main attributing factor to the large decrease in the volume is hydration of both polar and hydrophobic groups in the catalytic interface, which became exposed to water in the open conformation. At moderate pressures, the unfolding is reversible, but at pressures above $2.5 \mathrm{Kbar}$, subunit dissociation and irreversible denaturation are frequently observed.

\section{The overall crystal structure of Y74F and C298S}

Preliminary crystallographic characterization of the crystals of the two mutants using the HKL2000 [40] program package revealed that the unit cell is $118 \AA, 120 \AA$ and 171 $\AA$ and the space group is F222, similar to the apo wt Trpase [PDB: 2OQX]. Data collection and refinement statistics for the apo Y74F and C298S mutants are summarized in Table 4 . The crystal structures of the two mutants indicated that these Trpases are essentially identical and that the root mean square (RMS) of each of them with the apo Trpase [PDB: 2OQX] is about $0.3 \AA$. Efforts to crystallize the holo form of the wt Trpase and the Y74F and C298S mutants resulted in a low diffracting crystals. Analysis of the low resolution data revealed that these holo Trpases are found in two conformations suggesting low affinity to PLP.

Amino acid sequence comparison of $E$. coli Trpase with the $P$. vulgaris Trpase indicated that these two enzymes share a 52\% sequence identity [41], resulting in a similar crystal structure. However, superpositioning of the crystal structures of the wt apo E. coli Trpase, the two new mutants in their apo form and the holo P. vulgaris Trpase revealed significant differences in the relative orientation of the large and small domains (Figure 4). The two apo mutants of E. coli Trpases as well as the wt Trpase are found in an open conformation, different than that of the closed one found for P. vulgaris in its holo form. The RMS deviation for 464 Cás of the C298S mutant crystal structure with the Trpase from $P$. vulgaris (of subunit A) is 4.8 $\AA$, while the RMS deviation for each domain is $2.1 \AA$ for the large domain (for $260 \mathrm{Cas}$ ) and $1.1 \AA$ for the small domain (for 152 Cas of the small domain).

Additional significant differences among the holo Trpase from $P$. vulgaris and the apo wt E. coli Trpase were found in the conformation of the loop composed of residues 295-310 (E. coli numbering), and are shown in Figure 5. This region is found in two major conformations: one of the holo forms and one of the apo forms. In one of the wt apo crystal structures this loop is found in the same conformation as holo $P$. vulgaris Trpase. This suggests that the loop composed of residues $295-310$ is highly flexible and may be involved in the transition between the closed and open conformation. The flexibility of this region may account for the faster kinetics found for C298S mutant [28].

The PLP molecule is located in the inter domain cleft of one monomer and is coordinated by residues from a neighboring monomer [PDB: $1 \mathrm{AX} 4$ ] (Figure 6). The two monomers involved in the binding of the PLP molecule (subunits A and B, Figure 1) form a dimer resembling the aspartate aminotransferase (AATase) dimer [42]. This dimer is referred to as the catalytic dimer, while subunits $\mathrm{A}$ and $\mathrm{C}$ create the non-catalytic dimer (Figure 1). We have examined the interactions holding the monomers of $E$. coli Trpase along the catalytic and the non-catalytic interfaces [18]. The catalytic dimer (AB) is further stabilized by 
Table 4: Data collection and refinement statistics* for Y74F and C298S mutants of $E$. coli Trpase.

\begin{tabular}{|c|c|c|}
\hline & Y74F [PDB:2VIP] & C298S [pdb:2V0Y] \\
\hline \multicolumn{3}{|l|}{ Data collection } \\
\hline Space group & $\mathrm{F} 222$ & $\mathrm{~F} 222$ \\
\hline Wavelength & $1.5 \AA$ & $1.5 \AA$ \\
\hline \multirow[t]{6}{*}{ Unit cell } & $\mathrm{a}=118.7 \AA$ & $\mathrm{a}=120.5 \AA$ \\
\hline & $\mathrm{b}=120.2 \AA$ & $b=118.8 \AA$ \\
\hline & $c=171.7 \AA$ & $c=171.5 \AA$ \\
\hline & $\alpha=90^{\circ}$ & $\alpha=90^{\circ}$ \\
\hline & $\beta=90^{\circ}$ & $\beta=90^{\circ}$ \\
\hline & $\gamma=90^{\circ}$ & $\gamma=90^{\circ}$ \\
\hline Resolution & $500.0-1.90 \AA$ & $500.0-1.98 \AA$ \\
\hline Highest resolution shell & $1.97-1.90 \AA$ & 2. $05-1.98 \AA$ \\
\hline $\begin{array}{l}\text { Total number of measured reflections } \\
\text { Total number of independent reflections }\end{array}$ & $\begin{array}{l}155,699 \\
47,181\end{array}$ & $\begin{array}{l}186,657 \\
42,496\end{array}$ \\
\hline Completeness (\%) & $97.6 \%(97.8 \%)$ & $99.3 \%(96.5 \%)$ \\
\hline Rsym & $0.054(0.410)$ & $0.117(0.456)$ \\
\hline$I / \sigma(I)$ & $19.0(2.9)$ & $12.7(2.9)$ \\
\hline \multicolumn{3}{|l|}{ Refinement } \\
\hline Resolution range $(\AA)$ & $6.0-1.9$ & $8.0-2.0$ \\
\hline $\mathrm{R}(\%)$ & 19.14 & 21.48 \\
\hline$R_{\text {free }}(\%)$ & 22.72 & 22.09 \\
\hline Protein atoms & 3682 & 3678 \\
\hline Solvent atoms & 595 & 519 \\
\hline $\mathrm{Mg}^{2+}$ atoms & 1 & 1 \\
\hline $\mathrm{Cl}$-atoms & 1 & 1 \\
\hline \multicolumn{3}{|c|}{ RMS deviations from restraints target value } \\
\hline Bond length $(\AA)$ & 0.005 & 0.006 \\
\hline Bond Angle $\left({ }^{\circ}\right)$ & 1.21 & 1.22 \\
\hline $\begin{array}{l}\text { Average } B \text { factor } \\
\text { (for protein atoms) }\left(\AA^{2}\right)\end{array}$ & 28.8 & 28.9 \\
\hline
\end{tabular}

Data in parenthesis correspond to the high resolution shell.
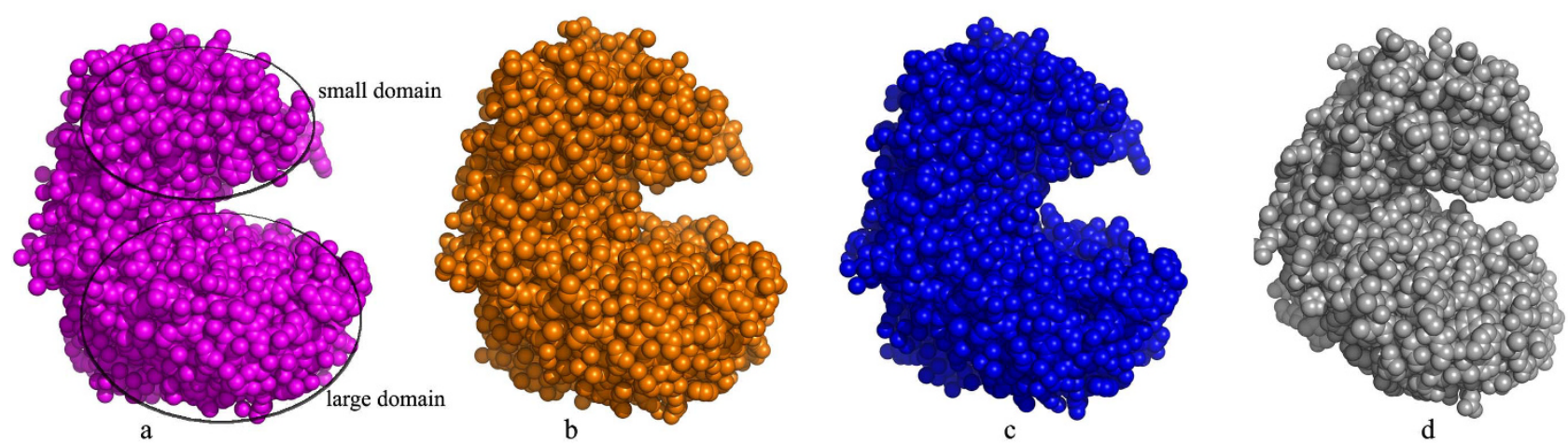

Figure 4

CPK presentation of the crystal structures of apo E. coli Trpases and holo P. vulgaris (a) mutant C298S (shown in magenta), (b) mutant Y74F (shown in orange), (c) apo wt E. coli (shown in blue) and (d) holo $P$. vulgaris Trpase (gray). This indicates that the two apo mutants of E. coli Trpases as well as the wt Trpase are found in an open conformation, different from the closed conformation found for P. vulgaris in its holo form. 


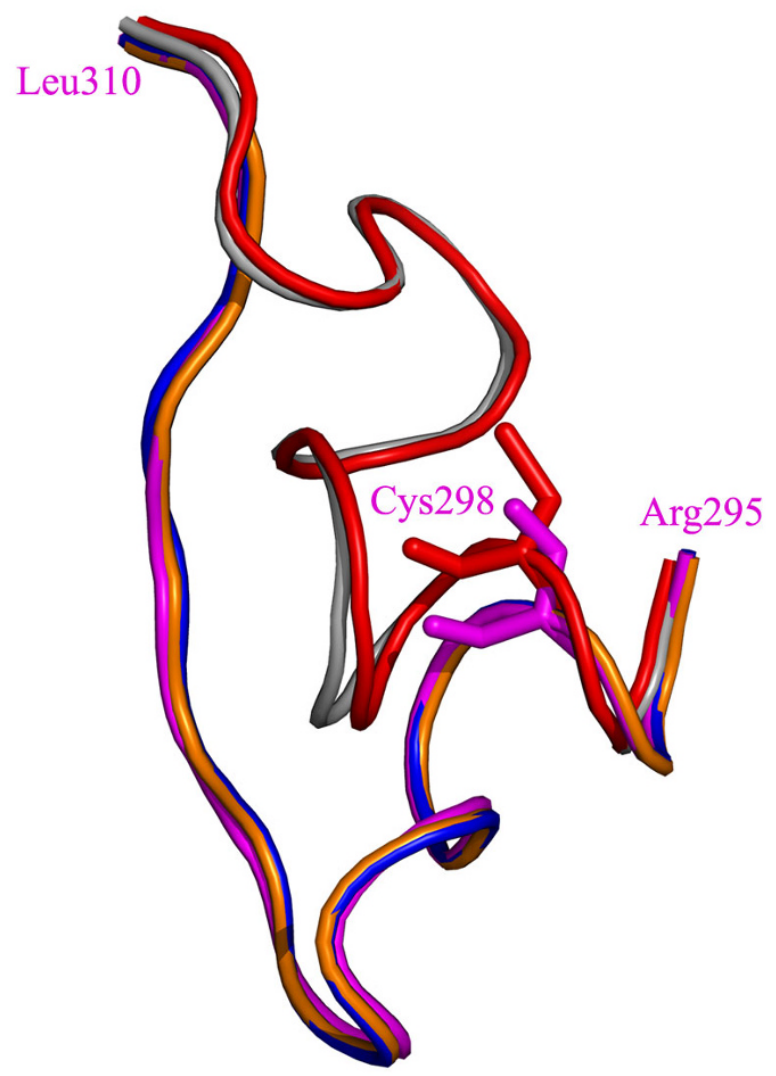

Figure 5

Different conformations of the loop composed of residue 295-3 I 0 (E. coli numbering). The apo wt $E$. coli loop is colored in blue, the mutant $\mathrm{Y} 74 \mathrm{~F}$ is colored in orange and C298S in magenta. The same region of holo $P$. vulgaris Trpase is (in gray) and apo wt $E$. coli (in red) indicating an additional conformation for this loop. The mutation site 298 is shown as sticks for the apo E. coli (red) and for the C298S mutant in magenta.

two hydrogen bonds between the hydroxyl groups of Tyr74 and Tyr307 from one subunit to the phosphate group of the PLP molecule from the neighboring subunit. Upon cooling and conformational change these hydrogen bonds are distorted and weakened.

On the non-catalytic interface there are numerous PLPindependent interactions that include the hydrogen bond network of a $\beta$-sheet formed by four $\beta$ strands between subunits A and $C$ (residues 12-17 and 58-60 from each subunit) and the hydrophobic interactions in this region include the side chains of Val15 and Val59 (Figure 7). These interactions along the non-catalytic interface are relatively far from the active site and the PLP binding site and as such are not affected by the binding or the release of PLP. Once E. coli Trpase undergoes a conformational change these strong hydrogen bonds and hydrophobic

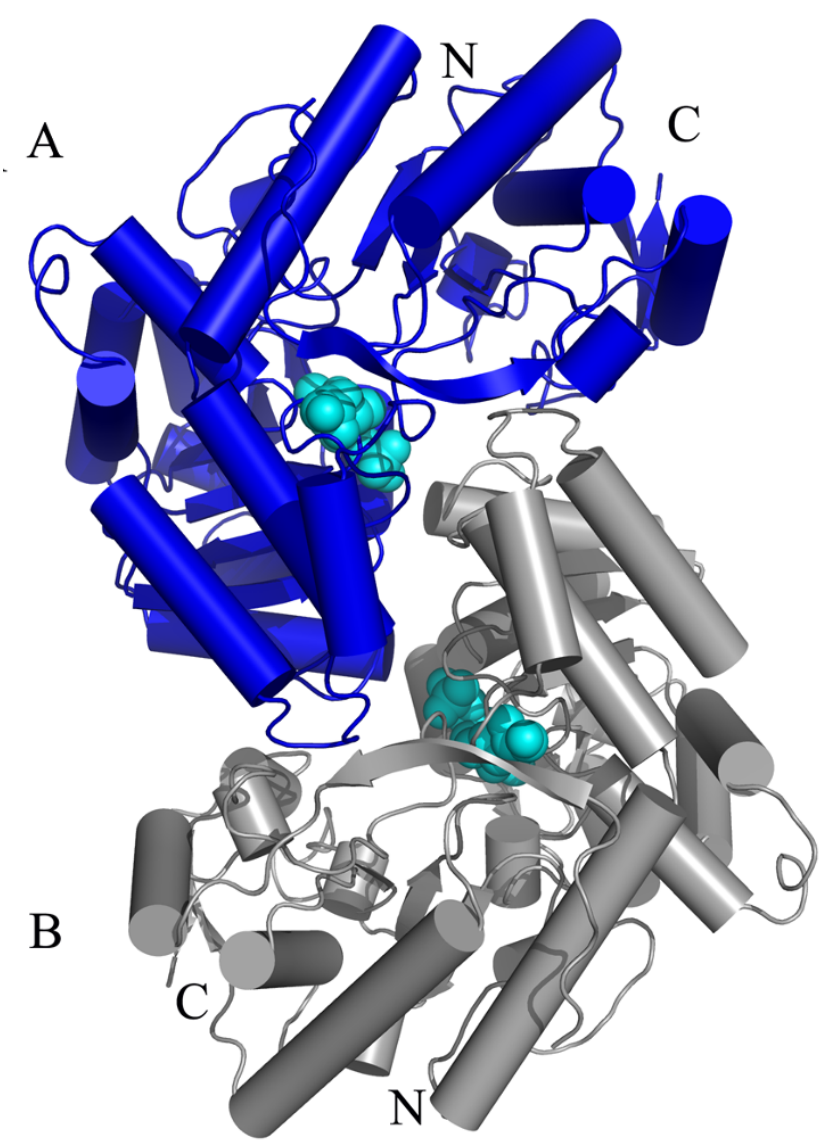

Figure 6

The catalytic dimer is composed of A and B molecules. The PLP molecule is located in the inter domain cleft of one monomer and is coordinated by residues from a neighboring monomer.

interaction between the two subunits prevent further dissociation of the dimers to monomers. Thus, we suggest that upon cooling, the Trpase tetramer dissociates into the non-catalytic dimers (resulting in AC and BD dimers).

\section{Dissociation of $\mathbf{P}$. vulgaris Trpase}

We also examined the cold dissociation of apo Trpase from P. vulgaris and compared it to the cold dissociation of E. coli Trpase. Despite the similarity in the amino acid sequence between both enzymes they show different stability at low temperatures $\left(2^{\circ} \mathrm{C}\right)$. Trpase from $P$. vulgaris in its apo form dissociates further into monomers even at $25^{\circ} \mathrm{C}$ (Table 5). Cooling the P. vulgaris Trpase to $2^{\circ} \mathrm{C}$ for $24 \mathrm{~h}$ augmented the dissociation into monomers. This is in sharp contrast to the E. coli Trpase which dissociates to dimers only.

Analysis of the non-catalytic interface in both Trpases (from E. coli and P. vulgaris) revealed that the $\beta$-sheet 


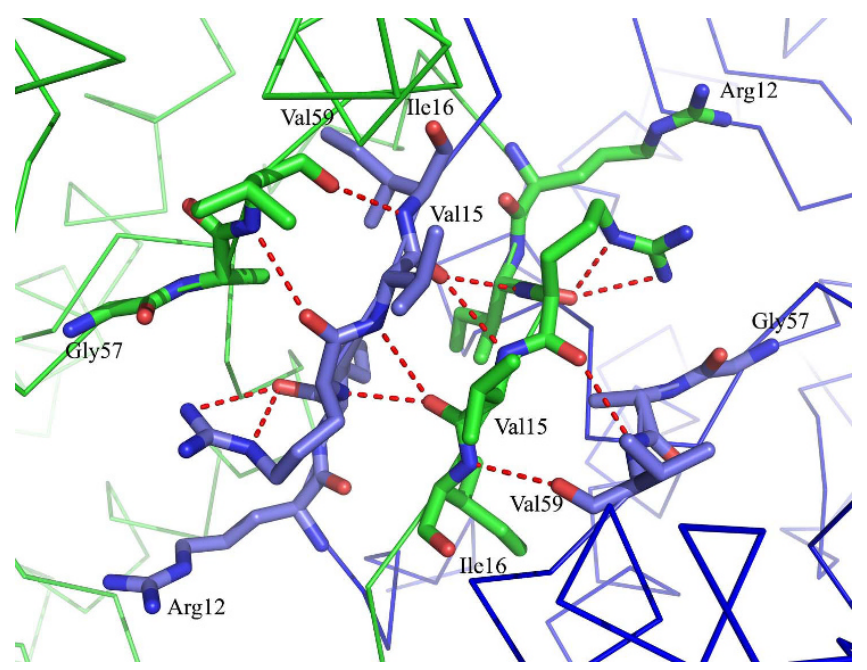

Figure 7

The $\beta$ sheet at the non-catalytic interface is formed by two anti parallel $\beta$ strands from subunits $A$ (shown in blue) and $\mathbf{C}$ (shown in green). This hydrophobic core is not exposed to the solvent and accounts for the dissociation of $E$. coli Trpase to dimers only.

located at the core of the tetramer is not exposed to the solvent. Furthermore, the four $\beta$-strands are structurally similar, but differ in their amino acid content. Met57, Met13 and Val14 of $P$. vulgaris Trpase are replaced by Val59 and Val15 and Ile16 in the E. coli Trpase (Table 2). The two valine residues and the isoleucine residue of $E$. coli Trpase are more hydrophobic (see table 2) than the corresponding two methionine residues and the valine residue of $P$. vulgaris [30]. Thus, the presence of the more hydrophobic core in the region of the non-catalytic interface of $E$. coli presumably leads to a higher stability of the dimeric structure of apo Trpase from E. coli compared to Trpase of P. vulgaris.

\section{Discussion}

At low temperatures and low concentrations E. coli Trpase undergoes a reversible loss of activity, followed by dissociation into dimers. Complete dissociation/inactivation occurred after incubation for $20 \mathrm{~h}$ at $2{ }^{\circ} \mathrm{C}$ and association/ reactivation occurred upon warming for few hours. This was previously reported in a detailed time course study for both the wt Trpase and its W330F mutant [11,12,27]. To further explore the temperature driven changes in the hydrophobic interactions at the non-catalytic or at the catalytic interfaces of E. coli Trpase we examined the role of single point mutation at each interface on enzyme activity, dissociation and crystal structure.

Based on our kinetic and high pressure studies as well as the crystal structures, we propose the following mechanism for the cold inactivation of E. coli Trpase (Scheme 1)

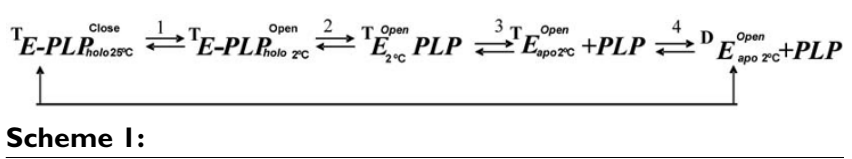

where TE-PLPclose is the holo tetrameric active Trpase at $25^{\circ} \mathrm{C}$ in a close conformation; ${ }^{\mathrm{T}} \mathrm{E}-\mathrm{PLP}$ open is the holo tetrameric enzyme in the open conformation at $2{ }^{\circ} \mathrm{C}$; ${ }^{\mathrm{T}} \mathrm{E} \cdots \mathrm{PLP}$ is the non-covalently bound complex in an open conformation and ${ }^{\mathrm{T}} \mathrm{E}$ is the apo enzyme in an open conformation at $2^{\circ} \mathrm{C}$. Step 4 is the dissociation of the tetrameric form to dimers, ${ }^{\mathrm{T}} \mathrm{E}$ to $\mathrm{DE}$.

Cooling (step 1) weakens the hydrophobic interactions resulting in a conformational change and a corresponding modified solvation. The change from the closed to an open conformation is associated with a reduction in the tight packing of the tetramer and is enhanced by the point mutations. This conformational change is further supported by the present high pressure studies showing that increasing hydrostatic pressure has the same effect as decreasing temperature in affecting the conformational equilibrium.

The conformational change at low temperatures results in breaking the covalent aldimine bond between residue Lys270 (E. coli numbering) and the PLP molecule (step 2). This overcomes the rest of the non-covalent binding interactions between PLP and Trpase, and results in the separation of the PLP from the active site (step 3) leading to dissociation into dimers (step 4). This suggested sequence for PLP-Trpase interactions is further supported by HPLC-

Table 5: The effects of cooling and reactivation on the degree of dissociation of apo wt Trpase from $E$. coli and $P$. vulgaris

\begin{tabular}{lllcr}
\hline Sample & $\mathbf{T}\left({ }^{\circ} \mathbf{C}\right)$ & \multicolumn{2}{c}{ Degree of dissociation (\%) } \\
& & Tetramer & dimmer & monomer \\
\hline P. vulgaris Trpase & & $37.3 \pm 1.2$ & $44.5 \pm 3.4$ & $18.2 \pm 4.0$ \\
P. vulgaris Trpase & $25^{\circ} \mathrm{C}$ & $21.7 \pm 0.6$ & $45.4 \pm 0.7$ & $32.9 \pm 1.6$ \\
P. vulgaris Trpase +I mM PLP & $2{ }^{\circ} \mathrm{C}, 24 \mathrm{~h}$ & $92.6 \pm 0.8$ & $7.4 \pm 0.2$ & - \\
E. coli Trpase & $25^{\circ} \mathrm{C}, 2 \mathrm{~h}$ & $30.0 \pm 2.2$ & - \\
E. coli Trpase + I mM PLP & $25^{\circ} \mathrm{C}$ & $100 \pm 0.6$ & - \\
\hline
\end{tabular}

Data in parenthesis correspond to the high resolution shell. 
Diode array profiles which could not detect PLP-bound dimers.

Our results suggest that even minor changes in the size of the amino acid side chain reduce the tight fit that is presumably required for the stability of the holo tetrameric enzyme. The reduced fit due to mutations along the two symmetry axis resulted in a higher vulnerability to cooling, which enhances the dissociation and the release of PLP. Changes in side chain hydrophobicity in the present mutants were found to be less relevant to the stability of the tetramer.

We also compared the dissociation of the wt and the three mutants in their apo form and found that their dissociation into dimers occurs even at $25^{\circ} \mathrm{C}$ to the same extent (Table 3). Upon cooling of the apo forms to $2^{\circ} \mathrm{C}$, an additional dissociation of about $15 \%$ was observed. The effect of the point mutation on the cold dissociation was observed only in the holo form. We found that at $2^{\circ} \mathrm{C}$, a factor of 3 in the extent of dissociation was observed between the wt and its mutated holo forms (Table 3 ). The loss of PLP overshadows the relative small contributions of the different interactions in the mutants, suggesting that these interactions at both interfaces have a relatively minor effect on the cold dissociation of E. coli Trpase.

In contrast to the similarity found in the degree of cold inactivation, dissociation (Tables 1\&3) and the crystal structures (Figure 5), differences were observed in the kinetics of cold inactivation and dissociation between the mutants and the wt Trpase (Figure 2). The location of the point mutation, i.e. on the catalytic (C298S) vs. the noncatalytic (W330F) axis, affects primarily the kinetics of cold lability. Notably, while a qualitative correlation was observed between the kinetics of cold inactivation and dissociation, it does not follow a quantitative relationship. While cold inactivation is a direct result of primarily the enamine PLP-Lys270 scission, the following collapse of the quaternary structure into dimers results from numerous protein-protein and protein-solvent interactions including hydrophobic, electrostatic and hydrogen bonds. A detailed description of this multi-step process requires the study of additional point mutations.

To summarize, the observed cold lability of $E$. coli Trpase results from the release of PLP and from the preclusion of the tight assembly of the tetramer. The wild-type system is balanced to favor the tetramer stabilization, and even a small perturbation of the interaction energy causes it to shift toward dimers.

\section{Conclusion}

The cold inactivation and dissociation of holo E. coli Trpase is mainly affected by the release of the cofactor PLP. In the absence of PLP variable packing-interactions on the monomers' interface due to the mutation $(\mathrm{Y} 74 \mathrm{~F}$, C298S and W330F) make additional, relatively small contribution to the cold dissociation of E. coli Trpase to dimers. The hydrophobic interactions along the non-catalytic interface may account for the difference in dissociation into dimers $v$ s. monomers in $E$. coli and $P$. vulgaris Trpases.

\section{Methods \\ Materials}

S-(o-nitrophenyl)-L-cysteine (SOPC) was synthesized as described previously [43]. PLP, Tricine, L-tryptophan, 2mercaptoethanol, protamine sulfate, ampicillin, buffers and $\left(\mathrm{NH}_{4}\right)_{2} \mathrm{SO}_{4}$ were purchased from Sigma. Other chemicals obtained from various commercial suppliers were of pure or extra pure grade.

\section{Enzyme purification}

Wild-type Trpase was isolated from E. coli SVS 370 cells containing the tnaA gene on plasmids by a procedure described previously [44]. Additional purification was achieved by anion exchange chromatography on DEAESephadex A-50 or DEAE-Sepharose 4B-CL, and size exclusion chromatography on Sephacryl S-300-HR [11,45]. The protein fractions with the highest specific activity and homogeneity in SDS polyacrylamide gel electrophoresis (greater than $97 \%$ purity) were combined and concentrated by total precipitation with $\left(\mathrm{NH}_{4}\right)_{2} \mathrm{SO}_{4}$ or in an Amicon ultrafiltration YM-30 membrane and frozen in $0.3-\mathrm{ml}$ aliquots at $-80^{\circ} \mathrm{C}$. W330F and $\mathrm{C} 298 \mathrm{~S}$ mutants of $E$. coli Trpase were isolated in the same way from E. coli SVS 370 cells containing the tnaA gene with the respective sitedirected mutation. The Y74F mutant was expressed under lac., on a pET17b plasmid in BL21(DE3) cells. Wild-type Trpase from $P$. vulgaris was isolated from E. coli SVS 370 cells containing the tryptophanase gene from $P$. vulgaris in the pAVK plasmid [41]. Protein concentration during purification was determined using the Bradford reagent [46] with BSA as a standard. The concentration of each purified enzyme (wt, C298S and Y74F) was determined at $278 \mathrm{~nm}$, taking the absorbance $\mathrm{A}^{1 \%}$ values of 9.19 for holo $P$. vulgaris and holo E. coli and 7.95 for apo $w t$-Trpases [44]. The concentration of W330F was determined using the value of 7.64 for the holo form [47]. The apo enzymes were prepared by overnight dialysis of the holo enzymes against $0.1 \mathrm{M}$ sodium phosphate-ethylenediamine buffer, $\mathrm{pH} 8.0$, at $4^{\circ} \mathrm{C}$.

\section{Enzymatic activity measurements}

Activity was measured by a spectrophotometric method with the chromogenic substrate analog, S-(o-nitrophenyl)-L-cysteine (SOPC), as described in Suelter et al., $[21,48]$ using the 8453A Hewlett Packard spectrophotometer connected to a UC-F-10 Julabo thermostated bath (JTB) $\left( \pm 0.1^{\circ} \mathrm{C}\right)$. A-10 $\mu$ l enzyme aliquots $(0.3-0.5 \mathrm{mg}$ protein/ml, specific activity $42-50 \mu \mathrm{mol} \mathrm{min}^{-1} \mathrm{mg}$ protein ${ }^{-1}$ ) were stirred into $1 \mathrm{ml}$ (final volume) of $0.6 \mathrm{mM}$ SOPC in 
$50 \mathrm{mM}$ potassium phosphate buffer, $\mathrm{pH} 8.0$, at $25^{\circ} \mathrm{C}$ and. Initial activity was measured for $1 \mathrm{~min}$ by following the decline in $\mathrm{OD}_{370 \mathrm{~nm}}\left(\Delta \varepsilon=-1.86 \times 10^{3} \mathrm{M}^{-1} \mathrm{~cm}^{-1}\right)$. One unit of Trpase is defined as the amount required for the decomposition of $1 \mu \mathrm{mol}$ SOPC to the product $o$-nitrothiophenolate in $1 \mathrm{~min}$ at $25^{\circ} \mathrm{C}$. The activity measurements related to cold inactivation were carried out as described above. The activities of the Trpases at $2{ }^{\circ} \mathrm{C}$ were measured within 30 to $60 \mathrm{sec}$, a time interval which is short enough to prevent reversibility of the cold-inactivated form. We previously have shown that the reactivation requires a minimum of $1 \mathrm{~h}$ of re-warming to $25^{\circ} \mathrm{C}[11,12,27,49]$. The concentrations of the wt Trpase and of W330F, C298S mutants were $0.3-0.5 \mathrm{mg} / \mathrm{ml}$, while the concentration of the Y74F mutant was $10-20 \mathrm{mg} / \mathrm{ml}$ [50].

\section{Time dependence of cold inactivation and dissociation}

The time dependence of cold inactivation of wt Trpase and its mutants were performed at $25^{\circ} \mathrm{C}$ in $50 \mathrm{mM}$ Tricine-KOH buffer at pH 7.5 containing $100 \mathrm{mM} \mathrm{KCl}$ (Tricine- $\mathrm{KCl}), 5 \mathrm{mM}$ 2-mercaptoethanol, $50 \mu \mathrm{M}$ PLP. The enzyme solution $(0.5-1 \mathrm{ml})$ was kept on ice and slightly stirred. Aliquots of $10-20 \mu \mathrm{l}$ were removed at various times for assay at $25^{\circ} \mathrm{C}$. The time profile of cold dissociation for the wt, C298S and W330F was followed by HPLC analysis as described below.

\section{HPLC measurements of dissociation degree for holo and apo Trpases}

HPLC analysis of Trpases was performed at $25^{\circ} \mathrm{C}$ and $2{ }^{\circ} \mathrm{C}$ with a Waters 99 supplied Photodiode Array detector UV using a gel filtration column BIOSEP-SEC S-3000 (7.5 $\times$ $600 \mathrm{~mm}$ ), equipped with a water jacket connected to a thermostated bath (UC-F-10 Julabo). Cold dissociation studies were carried out by incubating the enzymes for 20 $\mathrm{h}$ at $2{ }^{\circ} \mathrm{C}$ at a concentration of $1 \mathrm{mg} / \mathrm{ml}$ in Tricine- $\mathrm{KCl}, 2$ mM EDTA, 5 mM 2-mercaptoethanol and $50 \mu \mathrm{M}$ PLP. The HPLC column was loaded with $20 \mu$ l of Trpase in Tricine$\mathrm{KCl}$. The HPLC-chromatogram showed two peaks. The first displayed a PLP-bound characteristic absorption spectrum of the tetrameric form with maxima at 278, 337 and $420 \mathrm{~nm}$, and the second displayed a PLP-free enzyme peak, which is the dimeric form, characterized by the absence of the 337 and $420 \mathrm{~nm}$ peaks. Control samples incubated at $25^{\circ} \mathrm{C}$ for $1 \mathrm{~h}$ fully preserved their tetrameric structure. All data of specific activity and degree of dissociation are presented with the associated standard errors. HPLC measurements of apo Trpases were performed in the same buffer in the absence of PLP. The HPLC chromatogram of apo Trpases revealed two peaks with maximum absorbance at $278 \mathrm{~nm}$.

\section{High pressure studies}

The effect of hydrostatic pressure on the absorption spectra measured using a Cary 14 UV-VIS spectrophotometer modified by OLIS, Inc., containing a high-pressure cell from ISS (Champaign, IL) and equipped with a manual pressure pump. The cell was maintained at $25^{\circ} \mathrm{C}$ with an external circulating water bath. Samples $(1.2 \mathrm{ml})$ containing $1 \mathrm{mg} / \mathrm{ml}$ Trpase in $0.1 \mathrm{M}$ triethanolamine hydrochloride, $\mathrm{pH}$ 8.0, were enclosed in quartz bottles with a $9 \mathrm{~mm}$ path length immersed in spectroscopic ethanol as the pressurizing fluid.

The effect of pressure on the quaternary equilibrium was examined by incubating wt Trpase at elevated pressures, and following the changes in absorption spectrum as the PLP is released. Pressure affects equilibrium according to Eq. 1, where $K_{p}$ is the equilibrium constant at pressure $P$, $\mathrm{K}_{\mathrm{O}}$ is the pressure-independent value of the equilibrium constant, $\Delta \mathrm{V}_{\mathrm{o}}$ is the reaction volume change, $\mathrm{R}$ is the gas constant $(0.08314 \mathrm{l}$-bar/mol $\mathrm{K})$ and $\mathrm{T}$ the temperature in Kelvin [51]. The logarithmic form of Eq. 1 is given in Eq. (2). Thus, a plot of $\ln \mathrm{Kp}$ versus $P$ will give a straight line with a slope equal to $\Delta V \mathrm{o} / R T$ and intercept at $\ln \mathrm{K}_{\mathrm{o}}$.

$$
\begin{gathered}
K_{p}=K_{0} \exp \left(-P \Delta V_{0} / R T\right) \\
\ln K_{p}=\ln K_{0}-P \Delta V_{0} / R T \\
K_{p}=\left(A_{P}-A_{0}\right) /\left(A_{\infty}-A_{P}\right)
\end{gathered}
$$

The equilibrium constant can be related to the change in absorbance at a particular wavelength by Eq. 3 for simple two species equilibrium, where $A_{p}$ is the absorbance at pressure $\mathrm{P}, \mathrm{A}_{\mathrm{o}}$ is the absorbance at 0 bar, and $\mathrm{A}_{\infty}$ is the absorbance at infinite pressure. The values of $A_{\mathrm{o}^{\prime}} \mathrm{A}_{\infty}, \mathrm{K}_{\mathrm{eq}}$ and $\Delta \mathrm{V}_{\mathrm{o}}$ were obtained by global fitting of the spectra at all wavelengths from 300 to $550 \mathrm{~nm}$ throughout the entire range of pressures to Eq. 1 and 3 using the GlobalWorks program provided by OLIS, Inc. [52]. The protein concentration would be expected to increase with pressure because of the compressibility of water, which would result in a maximum increase in concentration of $4.7 \%$ at 1200 bar. However, the spectra were not corrected for the pressure effect, and the experimental results nonetheless fit well to the model, with low standard errors. The data also show an isosbestic point in the spectra, indicating that the concentration change due to pressure does not significantly affect the results.

\section{Crystallization of Y74F and C298S}

Crystallization experiments were carried out at $20^{\circ} \mathrm{C}$, and were set up using the hanging-drop vapor-diffusion method with siliconized cover-slips and Linbro 24-well tissue culture plates. Droplets ranging in size from 5 to 10 $\mu \mathrm{l}$ prepared by mixing equal volume of the protein solution and the reservoir solution and were equilibrated with $1.0 \mathrm{ml}$ of reservoir solution at room temperature $\left(20^{\circ} \mathrm{C}\right)$. 
The protein at concentration of $30-50 \mathrm{mg} / \mathrm{ml}$ in $50 \mathrm{mM}$ Tris, $100 \mathrm{mM} \mathrm{KCl} \mathrm{pH} \mathrm{7.5,} 2$ mM EDTA and $5 \mathrm{mM}$ 2-mercaptoethanol was mixed with the reservoir solution containing 30\%(w/v) PEG 400, 100 mM HEPES pH 7.5, 200 $\mathrm{mM} \mathrm{MgCl} 2,5 \mathrm{mM}$ 2-mercaptoethanol [45].

\section{Data collection and structure determination}

Crystals were transferred to Paratone oil (Hampton Research) and excess liquid was removed, followed by freezing in liquid nitrogen. Diffraction data set for the apo Y74F mutant was collected using a Rigaku RU3H rotating anode generator and MAR345 image plate detector at 100 K. For the apo C298S the diffraction data set was collected at low temperature $(100 \mathrm{~K})$ using a Raixs IV electronic area detector and a Rigaku RU-200 HB generator. Unit cell parameters, crystal orientation and integration of reflection intensities were determined using the HKL2000 package [40]. Refinement of the data was done using CNS [53] and manual corrections of the model were carried out with the graphics program $\mathrm{O}$ [54].

\section{Authors' contributions}

AK crystallized the mutants and determined their crystal structures. GYG isolated the enzymes and perform the HPLC studies. RCL participated in the kinetic data analysis and helped to draft the manuscript. YG participated in the crystal structure determination and analysis. RSP carried out the high pressure study and prepared the various mutants. AHP conceived of the study, participated in its design and coordination as well as helped to draft the manuscript. OA made substantial contributions to the design of the study, acquisition of crystallographic data, analysis and interpretation and writing the manuscript. All authors read and approved the final manuscript.

\section{Acknowledgements}

We gratefully thank Miss Marina de Leeuw for her most valuable contribution to the preparation of this manuscript. This work was partially support by the James Frank Foundation on - Light Matter Interaction, (to AHP), and by the Helen Soref and the Stanley Medical Research Foundations (to OA).

\section{References}

I. Bock PE, Frieden C: Another Look at Cold Lability of Enzymes. Trends in Biochemical Sciences 1978, 3(5): 100-103.

2. Bock PE, Gilbert HR, Frieden C: Analysis of the cold lability behavior of rabbit muscle phosphofructokinase. Biochem Biophys Res Commun 1975, 66(2):564-569.

3. Velichko IV, Volk SE, Dudarenkov VY, Magretova NN, Chernyak VY, Goldman A, Cooperman BS, Lahti R, Baykov AA: Cold Lability of the Mutant Forms of Escherichia-Coli Inorganic Pyrophosphatase. FEBS Lett 1995, 359(I):20-22.

4. Irias JJ, Olmsted MR, Utter MF: Pyruvate Carboxylase. Reversible Inactivation by Cold. Biochemistry 1969, 8( I 2):5 | 36-5 | 48.

5. Briganti F, Fong WP, Auld DS, Vallee BL: Invitro Dissociation and Reassociation of Human Alcohol-Dehydrogenase Class-I Isozymes. Biochemistry 1989, 28(13):5374-5379.

6. Shukuya R, Schwert GW: Glutamic acid decarboxylase. III. The inactivation of the enzyme at low temperatures. J Biol Chem 1960, 235: 1658-166I.

7. Burns RO, Demoss RD: Properties of tryptophanase from Escherichia coli. Biochim Biophys Acta 1962, 65:233-244.
8. Demoss JA: Studies on the mechanism of the tryptophan synthetase reaction. Biochim Biophys Acta 1962, 62:279-293.

9. Almog O, Kogan A, Leeuw M, Gdalevsky GY, Cohen-Luria R, Parola $\mathrm{AH}$ : Structural insights into cold inactivation of tryptophanase and cold adaptation of subtilisin S4I. Biopolymers 2008, 89(5):354-359.

10. Privalov PL, Makhatadze GI: Heat capacity of proteins. II. Partial molar heat capacity of the unfolded polypeptide chain of proteins: protein unfolding effects. J Mol Biol I990, 2 I 3(2):385-39I.

II. Erez T, Gdalevsky G, Torchinsky YM, Phillips RS, Parola AH: Cold inactivation and dissociation into dimers of Escherichia coli tryptophanase and its W330F mutant form. Biochim Biophys Acta 1998, I384(2):365-372.

12. Erez T, Phillips RS, Parola AH: Pyridoxal phosphate binding to wild type, W330F, and C298S mutants of Escherichia coli apotryptophanase: unraveling the cold inactivation. FEBS Lett 1998, 433(3):279-282.

13. Kunugi S, Tanaka N: Cold denaturation of proteins under high pressure. Biochim Biophys Acta 2002, I 595( (I-2):329-344.

14. King L, Weber G: Conformational drift of dissociated lactate dehydrogenases. Biochemistry 1986, 25(1 2):3632-3637.

15. King L, Weber G: Conformational drift and cryoinactivation of lactate dehydrogenase. Biochemistry 1986, 25(I 2):3637-3640.

16. Wolynes PG, Onuchic JN, Thirumalai D: Navigating the folding routes. Science 1995, 267(5204):1619-1620.

17. Franks F: Protein destabilization at low temperatures. Adv Protein Chem 1995, 46:105-139.

18. Isupov MN, Antson AA, Dodson EJ, Dodson GG, Dementieva IS, Zakomirdina LN, Wilson KS, Dauter Z, Lebedev AA, Harutyunyan $\mathrm{EH}$ : Crystal structure of tryptophanase. J Mol Biol 1998 , 276(3):603-623.

19. Hogberg-Raibaud A, Raibaud O, Goldberg ME: Kinetic and equilibrium studies on the activation of Escherichia coli KI 2 tryptophanase by pyridoxal 5'-phosphate and monovalent cations. J Biol Chem 1975, 250(9):3352-3358.

20. Suelter $\mathrm{CH}$, Snell EE: Monovalent cation activation of tryptophanase. J Biol Chem 1977, 252(6): | 852-I857.

21. Suelter $\mathrm{CH}$, Wang J, Snell EE: Application of a direct spectrophotometric assay employing a chromogenic substrate for tryptophanase to the determination of pyridoxal and pyridoxamine 5'-phosphates. Anal Biochem 1976, 76(I):221-232.

22. Toraya T, Nihira T, Fukui S: Essential Role of Monovalent Cations in the Firm Binding of Pyridoxal 5'-Phosphate to Tryptophanase and P-Tyrosinase. Eur J Biochem 1976, 69:4I I-4I9.

23. Phillips RS: The Mechanism of Tryptophan Indole-lyase: Insights from Pre-steady-state Kinetics and Substrate and Solvent Isotope Effects. J Am Chem Soc 1989, I I I:727-730.

24. Phillips RS, Bender SL, Brzovic P, Dunn MF: Mechanism of binding of substrate analogues to tryptophan indole-lyase: studies using rapid-scanning and single-wavelength stopped-flow spectrophotometry. Biochemistry 1990, 29(37):8608-86|4.

25. Phillips RS, Demidkina TV, Faleev NG: Structure and mechanism of tryptophan indole-lyase and tyrosine phenol-lyase. Biochim Biophys Acta 2003, I 647(1-2): I67-I72.

26. Phillips RS, Demidkina TV, Zakomirdina LN, Bruno S, Ronda L, Mozzarelli A: Crystals of tryptophan indole-lyase and tyrosine phenol-lyase form stable quinonoid complexes. J Biol Chem 2002, 277(24):2 I 592-21597.

27. Erez T, Gdalevsky GY, Hariharan C, Pines D, Pines E, Phillips RS, Cohen-Luria $\mathrm{R}$, Parola $\mathrm{AH}$ : Cold-induced enzyme inactivation: how does cooling lead to pyridoxal phosphate-aldimine bond cleavage in tryptophanase? Biochim Biophys Acta 2002, I 594(2):335-340.

28. Ku SY, Yip P, Howell PL: Structure of Escherichia coli tryptophanase. Acta Crystallogr D Biol Crystallogr 2006, 62(Pt 7):814-823.

29. Tsesin N, Kogan A, Gdalevsky GY, Himanen JP, Cohen-Luria R, Parola $\mathrm{AH}$, Goldgur $\mathrm{Y}$, Almog O: The structure of apo tryptophanase from Escherichia coli reveals a wide-open conformation. Acta Crystallogr D Biol Crystallogr 2007, 63(Pt 9):969-974.

30. Black SD, Mould DR: Development of hydrophobicity parameters to analyze proteins which bear post- or cotranslational modifications. Anal Biochem 1991, 193(I):72-82.

31. Gekko K, Tamura Y, Ohmae E, Hayashi H, Kagamiyama H, Ueno H: A large compressibility change of protein induced by a single amino acid substitution. Protein Science 1996, 5(3):542-545. 
32. Saito M, Kono H, Morii H, Uedaira H, Tahirov TH, Ogata K, Sarai A: Cavity-filling mutations enhance protein stability by lowering the free energy of native state. Journal of Physical Chemistry $B$ 2000, 104(I5):3705-37II.

33. Atta-Asafo-Adjei E, Daldal F: Size of the amino acid side chain at position I 58 of cytochrome $b$ is critical for an active cytochrome bcl complex and for photosynthetic growth of Rhodobacter capsulatus. Proc Natl Acad Sci USA I 99I, 88(2):492-496.

34. Kulikova VV, Zakomirdina LN, Dementieva IS, Phillips RS, Gollnick PD, Demidkina TV, Faleev NG: Tryptophanase from Proteus vulgaris: the conformational rearrangement in the active site, induced by the mutation of Tyrosine 72 to phenylalanine, and its mechanistic consequences. Biochim Biophys Acta 2006, I 764(4):750-757

35. Phillips RS, McPhie P, Miles EW, Marchal S, Lange R: Quantitative effects of allosteric ligands and mutations on conformational equilibria in Salmonella typhimurium tryptophan synthase. Arch Biochem Biophys 2008, 470(I):8-19.

36. Phillips RS, Miles EW, Holtermann G, Goody RS: Hydrostatic pressure affects the conformational equilibrium of Salmonella typhimurium tryptophan synthase. Biochemistry 2005, 44(2I):792I-7928.

37. Frye KJ, Royer CA: Probing the contribution of internal cavities to the volume change of protein unfolding under pressure. Protein Sci 1998, 7(10):2217-2222.

38. Matsuo H, Suzuki Y, Sawamura S: Solubility of alpha-amino acids in water under high pressure: glycine, L-alanine, L-valine, Lleucine, and L-isoleucine. Fluid Phase Equilibria 2002, 200(2):227-237.

39. Rother K, Preissner R, Goede A, Frommel C: Inhomogeneous molecular density: reference packing densities and distribution of cavities within proteins. Bioinformatics 2003 19(16):2112-2121.

40. Otwinowski Z, Minor W: Processing of X-ray diffraction data collected in oscillation mode. Methods in Enzymology 1997, 276:307-326.

4I. Kamath AV, Yanofsky C: Characterization of the tryptophanase operon of Proteus vulgaris. Cloning, nucleotide sequence, amino acid homology, and in vitro synthesis of the leader peptide and regulatory analysis. I Biol Chem 1992 267(28): 19978-19985.

42. Kirsch JF, Eichele G, Ford GC, Vincent MG, Jansonius JN, Gehring H, Christen P: Mechanism of action of aspartate aminotransferase proposed on the basis of its spatial structure. J Mol Biol 1984, 174(3):497-525.

43. Phillips RS, Ravichandran K, Vontersch RL: Synthesis of L-Tyrosine from Phenol and S-(Ortho-Nitrophenyl)-L-Cysteine Catalyzed by Tyrosine Phenol-Lyase. Enzyme and Microbial Technology I 989, I I (2):80-83.

44. Phillips RS, Gollnick PD: Evidence that cysteine $\mathbf{2 9 8}$ is in the active site of tryptophan indole-lyase. I Biol Chem 1989 264( I 8): I 0627-10632.

45. Kogan A, Gdalevsky GY, Cohen-Luria R, Parola AH, Goldgur Y: Crystallization and preliminary $X$-ray analysis of the apo form of Escherichia coli tryptophanase. Acta Crystallogr D Biol Crystallogr 2004, 60(Pt I I):2073-2075.

46. Bradford MM: A rapid and sensitive method for the quantitation of microgram quantities of protein utilizing the principle of protein-dye binding. Anal Biochem 1976, 72:248-254

47. Phillips RS, Gollnick P: The environments of Trp-248 and Trp$\mathbf{3 3 0}$ in tryptophan indole-lyase from Escherichia coli. FEBS Lett 1990, 268(I):213-216.

48. Suelter $\mathrm{CH}$, Wang J, Snell EE: Direct spectrophotometric assay of tryptophanase. FEBS Lett 1976, 66(2):230-232.

49. Edwards RA, Jickling G, Turner RJ: The light-induced reactions of tryptophan with halocompounds. Photochem Photobiol 2002, 75(4):362-368.

50. Raibaud O, Goldberg ME: The tryptophanase from Escherichia coli K-I 2. II. Comparison of the thermal stabilities of apoholo-, and hybrid enzymes. I Biol Chem 1973, 248(I0):345I-3455.

51. Phillips RS, Holtermann G: Differential effects of temperature and hydrostatic pressure on the formation of quinonoid intermediates from L-Trp and L-Met by H463F mutant Escherichia coli tryptophan indole-lyase. Biochemistry 2005 , 44(43): | 4289- | 4297
52. Matheson IBC, Desa RJ: Robust Multivariate-Analysis Applied to Separation of Components in Absorption-Spectra. Computers \& Chemistry 1990, I4(2): I57-164.

53. Brunger AT, Adams PD, Rice LM: Recent developments for the efficient crystallographic refinement of macromolecular structures. Curr Opin Struct Biol 1998, 8(5):606-6II.

54. Jones TA: A graphics model building and refinement system for macromolecules. J Appl Crystallogr 1978, I I:268-272.

55. Kyte J, Doolittle RF: A simple method for displaying the hydropathic character of a protein. J Mol Biol I982, I57(I): 105-132.
Publish with Bio Med Central and every scientist can read your work free of charge

"BioMed Central will be the most significant development for disseminating the results of biomedical research in our lifetime. "

Sir Paul Nurse, Cancer Research UK

Your research papers will be:

- available free of charge to the entire biomedical community

- peer reviewed and published immediately upon acceptance

- cited in PubMed and archived on PubMed Central

- yours - you keep the copyright
BioMedcentral 